\title{
A PASSAGEM PELO SISTEMA DE ENSINO EM TRÊS GERAÇŌES: CLASSE E GÊNERO NA SEGMENTAÇÃO DO SISTEMA DE ENSINO
}

\author{
Graziela Serroni Perosa
}

\begin{abstract}
RESUMO: Este artigo analisa os investimentos educativos diferenciados, realizados por três gerações de famílias inseridas em um grupo socialmente privilegiado. A análise centra-se na discussão de como, de uma geração a outra, a passagem pelo sistema de ensino esteve na base dos processos de diferenciação social entre os indivíduos. O material empírico trabalhado foi obtido no quadro de uma pesquisa de doutorado, na qual identifiquei a escola de nível secundário e as trajetórias sócio-profissionais de oitenta e duas mulheres, ex-alunas de três escolas católicas de São Paulo. Discute se modificações estruturais, de longa duração, tais como a expansão do acesso ao ensino, o investimento crescente das meninas nos caminhos da escolarização e a conotação sexual dos percursos escolares. Por meio da comparação sistemática da passagem pelo sistema de ensino e de ingresso no ensino superior é possível verificar a maneira pela qual a ordem social foi transposta para o universo escolar definindo os horizontes possíveis para cada um.

Palavras-chave: Sistema de ensino. Classe. Gênero. Geração.
\end{abstract}

THE PASSAGE OF THREE GENERATIONS THROUGH THE SCHOOLING SYSTEM:

CLASS AND GENDER IN THE SEGMENTATION OF THE SCHOOLING SYSTEM

ABSTRACT: This paper analyses the different educational investments made by three generations of families included in a socially privileged group. It discusses how, from one generation to the other, passing through the education system was the basis of the social differentiation processes among individuals. The empirical material studied was obtained as part of a doctoral research,

Doutora em Educação e professora da Escola de Artes, Ciências e Humanidades da Universidade de São Paulo (USP).E-mail: gperosa@usp.br 
A passagem pelo sistema de ensino em três gerações...

which identified the secondary school level and socio-professional trajectories of eighty-two women who had studied in three Catholic schools. It focuses on the structural long-duration changes, such as the expanding access to education, the increased investment in girls' schooling paths and the survival of the sexual connotation of school courses. By systematically comparing the passage through the education system and the enrollment in higher education, it shows how the social order was transferred into the school environment and how it defines the possible horizons for each person.

Keys words: Effects of education. Class. Gender. Generation.

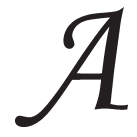

expansão do acesso à escola e o prolongamento da escolarização das últimas três décadas do século passado, no Brasil, colocam a instituição escolar, ou, simplesmente, a "educação", no epicentro da dinâmica da estratificação social e da produção das desigualdades sociais (IBGE, 2004). A difusão do ensino é uma dessas transformações históricas que produz efeitos sobre todos, dos mais velhos aos mais novos, nos diferentes grupos sociais, homens e mulheres, brancos e negros são ou serão, mais ou menos, valorizados a partir de suas credenciais educacionais (Attias-Donfut, Lapierre \& Segalen, 2002). Neste artigo, utilizo o caso específico de um grupo de quarenta famílias, brancas, socialmente privilegiadas, altamente escolarizadas, residentes em São Paulo por volta de 1960, para pensar as divisões e subdivisões do sistema de ensino. Em pequena escala, podemos identificar configurações específicas do sistema de ensino na cidade e os percursos, depois da escola, de três geraçôes destas famílias. A oferta escolar da cidade é tomada como um todo socialmente hierarquizado que tende a produzir efeitos de destinos, agindo, consequentemente, sobre os processos de diferenciação e de mobilidade social, no interior de um contexto histórico específico (Ringer, 1979; Bourdieu, 1989). A observação das qualificações educacionais, em três gerações dessas famílias, é útil para pensar, os diferentes usos e alguns efeitos importantes associados à passagem pelo sistema de ensino.

Não é de hoje que a passagem pelos sistemas de ensino, no Brasil e em muitos outros países, estrutura as divisões sociais (Weber, 1974; Mills, 1951; Bourdieu, 1970). Durante muito tempo, uma das 
principais fronteiras que distinguiam a população brasileira eram as distâncias entre os alfabetizados e os não alfabetizados, os instruídos e os não instruídos, os egressos dos cursos clássico/científico e dos cursos técnicos. A segmentação interna dos sistemas de ensino diz respeito às escolas e programas paralelos que se distinguem pela origem social, pelo sexo e pelo destino social dos alunos (Ringer, 2003). Diferenças produzidas pela passagem por um sistema de ensino desigual, que afetam decisivamente a definição dos papéis sociais, evidenciando o componente propriamente escolar destas definições. São fronteiras sociais e simbólicas, produzidas coletivamente e que, portanto, são históricas, em movimento, contingenciais, mas, ao mesmo tempo, possuem raízes antigas e duráveis que sobrevivem (Saint-Martin \& Gheorghiu, 2010). Este artigo se insere nessa linha de preocupação e procura discutir, a partir da análise empírica de um grupo socialmente determinado, as hierarquias produzidas no interior do sistema de ensino e seus efeitos sobre percursos sociais. Examinam-se alguns dados sobre a passagem pelo sistema de ensino brasileiro de três geraçóes familiares, adultas, pertencentes às camadas de alta renda e residentes na capital paulista na década de 1960. O grupo reunido de famílias $(n=40)$ já estava, há pelo menos duas gerações, em uma posição social privilegiada, mais ou menos sólida e estável. Eram famílias chefiadas pelos homens das dinastias de fazendeiros, mas também por profissionais liberais das profissōes imperiais (Direito, Engenharia e Medicina), industriais e comerciantes bem sucedidos que chegaram à cidade de São Paulo, muitos no intenso movimento de imigração que caracterizou a virada do século XIX para o XX nesta cidade.

A perspectiva comparativa favorecida em uma análise intergeracional é especialmente adequada, porque permite olhar também para as configurações específicas do sistema de ensino, em um dado espaço geográfico - São Paulo - caracterizado por profundas modificações econômicas e sociais, no período analisado. Como metrópole emergente, na primeira metade do século XX, São Paulo atraía as porções mais ricas da população brasileira, desde os grandes proprietários de terra, antigos senhores de escravos, até os grupos de imigrantes que ascenderam na cidade, por meio das atividades do comércio e da indústria. Eles compunham uma forte demanda por formas de escolarização, fechadas no "entre si", que deram origem a um complexo mercado escolar na cidade, em contexto histórico mais amplo, marcado pela difusão da 
A passagem pelo sistema de ensino em três gerações...

instrução e no qual as qualificações educacionais adquiriram peso decisivo na competição profissional.

O material empírico analisado foi reunido a partir de questionários, aplicados em 2002, entre oitenta e duas egressas de três escolas confessionais femininas de São Paulo. Para este artigo, foram selecionadas, deste conjunto, quarenta famílias cujos dados educacionais (escola frequentada, curso superior e ocupação) eram mais completos nas três gerações destas famílias. O grupo de mulheres que respondeu ao questionário, tratado aqui como geração-pivô (Attias-Donfut, Lapierre \& Segalen, 2002), nasceu entre 1937 e 1943 e terminou o ensino secundário por volta de 1960. Quando moças, foram confrontadas com a possibilidade concreta de prolongar a escolarização, ingressando no ensino superior brasileiro, em um momento caracterizado pela acentuada expansão do número de universitários no país e singularizado pelo crescente investimento feminino no prolongamento da escolarização. Elas foram abordadas a partir da construção de uma amostra de famílias, localizadas por meio da consulta aos arquivos escolares e com a ajuda de diferentes formas de organização de ex-alunas destas escolas. Depois de um primeiro contato pelo telefone, elas responderam a um longo questionário (15 páginas), com questões fechadas e abertas, sobre suas famílias. Este procedimento de pesquisa permitiu reconstruir, ainda que parcialmente, dados comparáveis das três gerações sobre a ocupação e a escolaridade de avós (maternos e paternos), nascidos por volta de 1880/1890, seus pais e mães, nascidos entre 1910/1920, e, de outro lado, seus irmãos e cônjuges, nascidos, em geral, nas décadas de $1940 / 1950$. Na análise dos resultados produzidos pela geraçãopivô, priorizam-se o tipo de formação educacional declarada e a ocupação de seus pais e avós, conjugadas no feminino e no masculino. Paralelamente à análise dos questionários, reuni dados pertinentes sobre a configuração específica do sistema de ensino no espaço da cidade, tendo submetido tais dados a uma análise fatorial de correspondência. Por meio destes dados, vemos modificaçóes mais amplas da sociedade brasileira, particularmente, aquelas ocorridas nos grandes centros urbanos que, à medida que cresciam e se desenvolviam economicamente, ampliaram também a concorrência no espaço educacional. Pelo diagrama apresentado na página 97 é possível notar algumas das principais oposiçôes simbólicas que subdividiam e hierarquizavam o espaço escolar da cidade neste período. 
Procura-se contribuir para pensar a hierarquia das carreiras escolares, dimensão raramente explorada nos estudos atuais sobre educação e desigualdade social, assentados sobre sólidos dados estatísticos que indicam o forte recrutamento, para os postos mais bem pagos do mercado de trabalho, dos indivíduos mais escolarizados no Brasil (Menezes Filho, 2001; Barros \& Mendonça, 2001). Tais estudos evidenciam os progressos nas estatísticas educacionais brasileiras, apontando para a situação de (quase) universalização do acesso e de prolongamento da escolarização da população brasileira. Procuro argumentar, com os dados dessa pesquisa, que tais análises se tornariam ainda mais precisas, se considerassem os efeitos diferenciados da passagem pelo sistema de ensino, com suas subdivisões e hierarquização interna. Identificando escola, instituição de ensino superior e o destino ocupacional de homens e mulheres destes grupos familiares, tento precisar a participação de diferentes configuraçôes do sistema de ensino no Brasil sobre as trajetórias individuais. Em um contexto de urbanização acelerada, de intensa diferenciação social, de organização do sistema de ensino, de estruturação de um acirrado mercado escolar, singularizado pela forte presença do segmento privado, procuro abordar a cidade de São Paulo como um espaço privilegiado para examinar os usos e os efeitos da passagem pelos sistemas de ensino, no interior de um dado grupo social. Trata-se, como veremos, de um espaço educacional em movimento de mudança, hierarquizado pela origem social e pelas relações de gênero, até o início da década de 1980, quando a coeducação de meninos e meninas se generalizou até mesmo entre as escolas católicas da cidade.

Classe e gênero na origem da segmentação do sistema de ensino

A primeira geração das famílias consideradas aqui nasceu por volta de 1880 e já era adulta na virada para o século Xx. Durante o Império, o ensino secundário era oferecido, em sua maioria, pela iniciativa privada e, a partir de meados de 1890, pelos seletos espaços dos Ginásios do Estado, cujo modelo no país sempre foi o Colégio de Pedro II, na capital carioca. Para esta geração, ser aprovado nos Ginásios do Estado dava acesso às fileiras mais prestigiadas do ensino superior brasileiro. Estas famílias compunham a demanda dos ginásios privados da cidade, católicos ou laicos, em alguns casos, mantidos por grupos de imigrantes e que podiam também dar acesso às profissões liberais. Nesta 
A passagem pelo sistema de ensino em três gerações...

época, dois terços dos brasileiros em idade escolar, dos dois sexos, estavam fora da escola e não haviam sido ainda alfabetizados. Entre as crianças, o número de meninas longe dos bancos escolares era ainda maior (Haidar, 2008). No Brasil, como na Europa, as meninas chegaram aos sistemas de ensino várias décadas depois dos meninos (Ariès, 1979). O acesso delas ao ensino superior, apesar de legal desde 1879, foi lento durante as primeiras décadas do século XX, tendo se acentuado apenas a partir da década de 1960. Entre as famílias aqui consideradas, a primeira distinção que se nota nessa geração é o atraso da escolaridade das mulheres (as avós, maternas e paternas) em relação aos homens do seu grupo social. Um terço dos avôs diplomados no ensino superior e nenhuma avó que tenha prolongado sua escolarização até a universidade. Mesmo com um crescente interesse na abertura de espaços de educação feminina, os ginásios particulares e, em São Paulo, a Escola Normal da Praça ${ }^{1}$ definiam, os limites do prolongamento dos estudos para as meninas desta geração. Se considerarmos que tais famílias estavam inseridas na parcela mais escolarizada da população brasileira, pode-se ver como foi lenta e gradativa a equiparação da escolaridade entre os sexos.

Mesmo se considerarmos a relativa fragilidade dos dados sobre a escolaridade na primeira geração, materializada na taxa de não resposta, algumas diferenças merecem atenção. Temos uma taxa de não respostas à escolaridade, na primeira geração, de 50\%. Além disso, o número de não respostas à escolaridade das avós foi muito superior às não respostas dos homens. Entre eles, um terço dos avôs já possuía ensino superior, quatro deles possuíam só o primário e dois haviam concluído o ginásio. É um dado significativo, se considerarmos que estas moças (casadas com os profissionais liberais e grandes proprietários rurais e urbanos da São Paulo, das primeiras décadas do século xx) eram, muito provavelmente, filhas das famílias mais abastadas e, portanto, com acesso possível às muitas escolas privadas que já existiam nesta época, na cidade. Tal "esquecimento", acerca da escolaridade das avós, está relacionado não às limitações do acesso à escola para meninas, mas ao fato de que, na memória familiar, os diplomas e os títulos escolares tendem a serem lembrados quanto mais altos e mais prestigiados eles forem. Por volta da década de 1920, a cidade já contava com muitas opções de escolas, sobretudo as católicas, mas também laicas, que exploravam o crescente interesse pela instrução feminina que caracterizou o final 
do século XIX e as primeiras décadas do século XX (Perosa, 2004). Entre as avós, as maiores formaçóes educacionais se deram na Escola Normal Caetano de Campos, ou ainda nos ginásios católicos. Em três casos, elas exerceram o magistério e, apenas excepcionalmente, elas prosseguiram na carreira após o casamento.

Entre os homens da primeira geração, um terço possuía o diploma superior. Em grande parte dos casos, tratava-se do prestigiado diploma de Direito, obtido em nove dos dez casos registrados, na Faculdade de Direito do Largo São Francisco, tradicional espaço de formação da elite política brasileira. Entre eles, temos ainda oito engenheiros, dos quais cinco foram alunos da Escola Politécnica de São Paulo, um deles havia estudado na Escola de Minas de Ouro Preto e outros dois casos, em cursos de Engenharia no exterior (Itália e Inglaterra). Também no caso destas escolas de Engenharia, sobretudo da Politécnica e da Escola de Minas, a notoriedade alcançada pelos seus ex-alunos conferia prestígio a essa formação no Brasil (Carvalho, 2002). Trilhar os circuitos mais prestigiados do sistema de ensino superior, no caso do grupo examinado, conduzia os homens ao exercício das profissões liberais, exercidas nesta época, por vezes, paralelamente a outras atividades econômicas, tanto que foram frequentes as inscriçōes do tipo "engenheiro e fazendeiro" ou "professor no Largo São Francisco até a compulsória, advogado e ex-deputado". Entre os avôs, grandes proprietários rurais, comerciantes e industriais, houve maior incidência de não resposta sobre o diploma, o que se explica por se tratar de atividades econômicas menos dependentes do capital escolar. Talvez, entre eles, as qualificaçôes educacionais não fossem muito altas e, por esta razão, não tenham sido lembradas.

\section{As hierarquias sobrevivem}

A segunda geração das famílias consideradas aqui (pais da geração-pivô) nasceu por volta de 1910, quando a cidade de São Paulo já se encontrava em pleno processo de expansão e de industrialização. A prosperidade descrita por historiadores e o consequente crescimento populacional, acentuados pela chegada de um grande contingente de estrangeiros na cidade, resultaram na formação de uma multidão de crianças e jovens. ${ }^{2}$ Em 1920, São Paulo possuía 600 mil habitantes e o número de crianças em idade escolar alcançava 104.283. A estimativa 
A passagem pelo sistema de ensino em três gerações...

era de que $40 \%$ delas não sabiam ler e escrever (IBGE, 2004). Datam deste período as primeiras grandes reformas do sistema de ensino, voltadas principalmente para a difusão da escola primária (Beisiegel, 1986), e a efervescência em torno dos ideais republicanos de educação (Azanha, 2004). ${ }^{3}$ A presença dos grupos escolares, responsáveis pelo primário, ainda que longe da quantidade necessária, se fazia notar em toda a cidade. ${ }^{4}$ No secundário, a situação não era muito distante da descrição de Haidar (2008) sobre o ensino secundário no Império, especialmente no que diz respeito à ampla atuação da iniciativa privada ${ }^{5}$ e ao prestígio associado aos seletos Ginásios do Estado, cujas vagas eram disputadas nos concorridos exames de admissão. Até 1940, o Ginásio do Estado de São Paulo era o único espaço de ensino secundário público da cidade (Spósito, 1984). Para as meninas, havia a Escola Normal da Praça e a Escola Normal do Brás, consideradas, à época, escolas profissionais e não secundárias, por isso não davam acesso ao ensino superior. ${ }^{6}$

A disposição de tais estabelecimentos de ensino na cidade expressa, de maneira emblemática, as distâncias que separavam a boa educação para os sexos feminino e masculino (São Paulo, 1914). Estas distâncias ficaram mais claras, quando relacionamos as propriedades escolares, como o programa de ensino, às propriedades sociais das escolas, tais como o bairro da cidade e o seu público potencial. O resultado obtido com a análise fatorial de correspondência nos permite dimensionar as homologias entre o espaço geográfico da cidade, a estrutura das posições sociais e a diferenciação escolar, aspectos extremamente interligados. Relacionando as propriedades sociais e as propriedades escolares, reconstruímos algumas das principais oposições simbólicas que subdividiam o espaço escolar neste contexto social. As variáveis consideradas foram a localização na cidade, a data de fundação, o público que recebiam, o programa de ensino, escola religiosa ou laica, a dependência administrativa (pública ou privada) e o tamanho dos estabelecimentos, variáveis construídas a partir da consulta aos Anuários do Ensino e outras fontes.

Como em boa parte das democracias antigas da Europa ocidental, as escolas secundárias da capital paulista se diferenciavam pelo público que recebiam, mas também pelos programas de ensino, como mostra a análise do diagrama a seguir: 


\section{Diagrama}

O espaço educacional da capital paulista, por volta de 1920

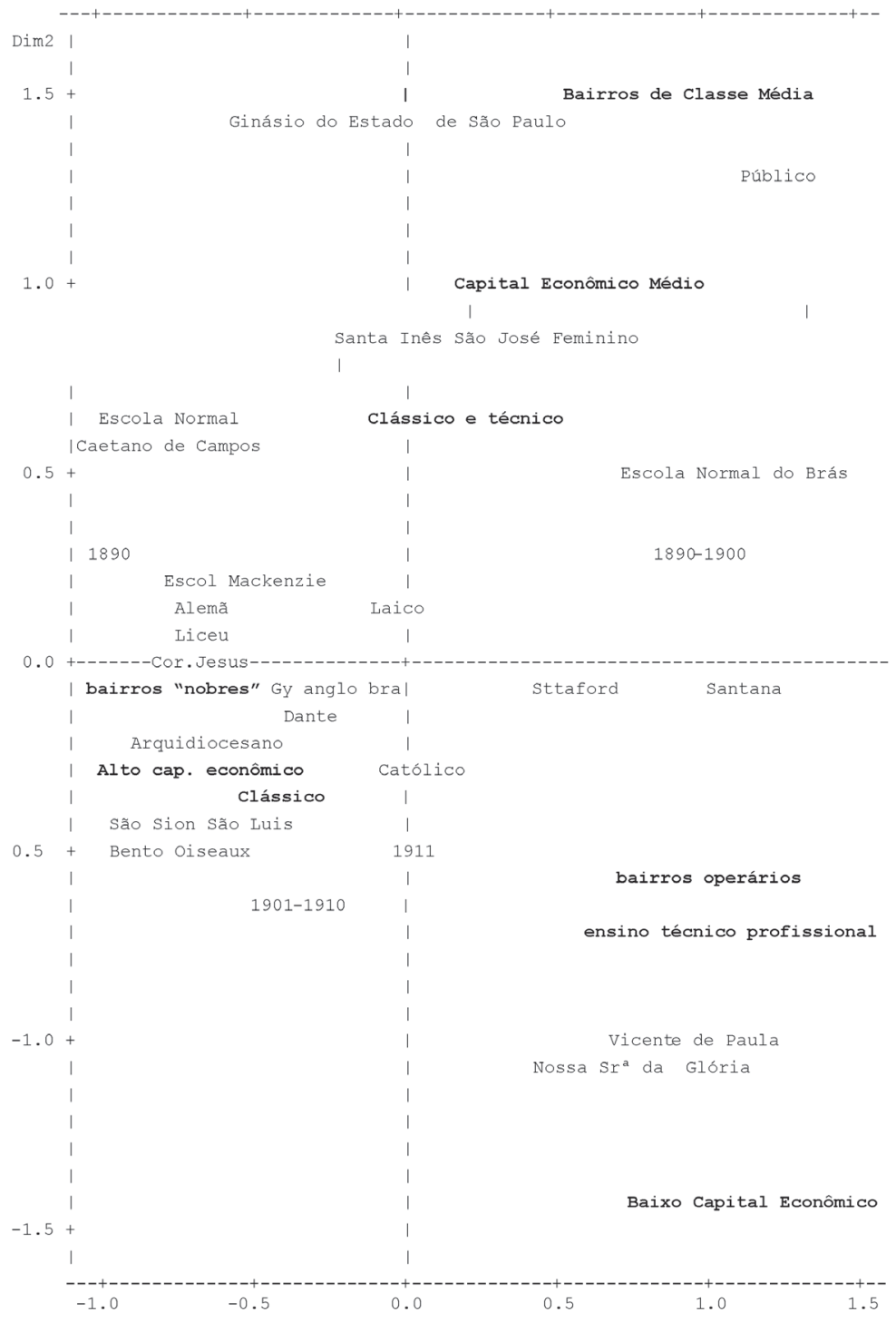

Educ. Soc., Campinas, v. 31, n. 111, p. 391-409, abr.-jun. 2010

Disponível em <http://www.cedes.unicamp.br> 
A passagem pelo sistema de ensino em três gerações...

O eixo horizontal opõe as escolas criadas nos bairros "nobres" às escolas instaladas na região leste da cidade, em bairros de concentração operária, tais como Brás, Penha e Cambuci. A variável "programa de ensino" contribuiu fortemente para a definição deste eixo, na medida em que o ensino técnico caracterizava, sobretudo, as escolas localizadas nos bairros de operários, que aparecem localizados nos quadrantes à esquerda do eixo vertical. Por meio deste procedimento, nota-se como a localização na cidade, a origem social dos alunos e as características do programa de ensino são variáveis cruciais na diferenciação e hierarquização interna deste espaço.

Se considerarmos a escolaridade dos pais $(n=40)$, nota-se um discreto predomínio da experiência escolar nos Ginásios do Estado, como o Ginásio da Capital, que aparece situado na parte superior do diagrama. Nesta geração, a frequência aos Ginásios do Estado, bem como aos grandes ginásios católicos ou laicos, conduzia os meninos para as fileiras mais prestigiadas do ensino superior. Foram quatorze pais egressos dos grandes Ginásios do Estado, seguidos por onze vindos dos ginásios católicos, com maior incidência dos colégios São Bento e São Luís. ${ }^{7}$ Sete pais vinham dos colégios privados laicos localizados no quadrante inferior esquerdo do diagrama (Rio Branco, Mackenzie e Liceu Franco Brasileiro). Apenas dois pais eram egressos do curso normal da escola Caetano de Campos. Foram estes circuitos do sistema de ensino que deram acesso à Escola Politécnica, diplomas de nove pais, à Faculdade de Medicina da UsP, diplomas de sete pais, ou à Escola de Direito do Largo São Francisco, caso de mais seis pais. Conta-se ao todo 21 pais que fizeram a graduação nos espaços simbolicamente mais valorizados do ensino.

Durante quase todo o século Xx, o sexo e a classe social foram critérios empregados para diferenciar os programas no interior do sistemas de ensino. Sabe-se que os currículos das escolas para meninas reservavam parte substancial do tempo às disciplinas que erigiam, em conteúdo escolar, a preparação para o casamento, a maternidade e as prendas domésticas como um todo. Mesmo as experiências escolares mais sofisticadas, voltadas para o público feminino, incluíam em seu programa de ensino o estudo das línguas (francês, latim, em geral, e, às vezes, italiano e alemão), como os programas de ensino voltados para os meninos, mas reservavam parte importante do tempo às disciplinas como o bordado, a pintura, o piano. A amputação de parte 
das disciplinas escolares produzia uma espécie de subcultura escolar, caracterizada pela restrição às aprendizagens intelectuais e pela dedicação suplementar de tempo e energia às disciplinas erigidas como femininas, o que terminava por canalizar a escolaridade das meninas a circuitos separados. ${ }^{8}$ Ao abolir a competição com os meninos e desencorajá-las aos cursos masculinos, estava em andamento "um programa de ensino baseado naquilo que as mulheres precisariam aprender para continuar a ser o que eram" (Muel-Dreyfus, 1996, p. 233), herança coletiva que sobreviveria por mais de uma geração.

As descriçõos de Lana sobre seus ascendentes ilustram bem como atributos e diferenças sociais, por meio do sistema de ensino, tornamse disposições e competências específicas. Seu avô paterno era egresso da Escola de Minas de Ouro Preto e sua avó paterna viera da Argentina e possuía o Ginásio como formação. "Fazendeiro de café, exportador, a vida toda" e "Dona de casa com 9 filhos. Bordava mas tinha empregadas, portanto, não trabalhava” foram as descrições das suas ocupações. Sobre sua avó materna: "Dona de casa. Teve 5 filhos. Fazia bastante tricô e gostava de cozinhar. Tinha empregadas"; sobre o avô materno, politécnico da escola de São Paulo: "engenheiro metalúrgico e secretário de obras da prefeitura da cidade". Nenhuma surpresa, o homem definido pela sua profissão e a mulher pela maternidade e sua vida doméstica. Já na geração dos pais, temos mais dados sobre a educação recebida por eles e a participação do sistema de ensino aparece com maior nitidez. A mãe de Lana, nascida em 1920, estudou primeiro no célebre Colégio Nossa Senhora do Patrocínio, de Itú, e fizera o colegial no Colégio Sion. Sobre suas atividades, Lana escreveu: "Dona de casa. Bordava. Lia...”, situação similar às meninas da geração anterior. O pai, ex-aluno do Colégio São Bento, já era a segunda geração de politécnicos da família. A descrição de suas atividades foi "Engenheiro civil. Construtor. Indústria de asfalto/aço, fazendeiro de laranjas e cavalos".

$\mathrm{Na}$ comparação entre homens e mulheres desta geração das famílias consideradas, um traço central é a distância entre trajetórias escolares femininas e masculinas, no interior do mesmo grupo familiar. Vemos, claramente, como se recriava a partir do sistema de ensino a "vocação" feminina à maternidade, ao cuidado da casa, dos sentimentos, ao mundo interior; reservando, aos homens, a razão, o preparo para o trabalho, para a ação no mundo exterior (cf. Bourdieu, 1999). Por 
A passagem pelo sistema de ensino em três gerações...

duas gerações do grupo pesquisado (pais e geração-pivô), as meninas eram mais frequentemente enviadas para as escolas católicas e os meninos, para espaços de educação mais concorridos, do ponto de vista escolar (o científico em oposição ao clássico e ao normal), e laicos. Entre as mães da geração-pivô, predominou uma origem escolar católica: entre as quarenta consideradas, quatorze eram ex-alunas dos antigos internatos católicos da cidade, seis de escolas privadas laicas e apenas duas egressas dos grandes ginásios públicos. Entre os pais, doze eram egressos dos seletos ginásios do estado, dez vinham dos ginásios católicos e nove egressos de ginásios laicos. Os meninos eram inseridos em circuitos escolares mais competitivos do ponto de vista escolar e a ênfase na educação das meninas era moral e não profissional.

A partir da década de 1930, surgiram as primeiras escolas católicas de ensino superior, voltadas para o público feminino e que funcionavam como uma espécie de prolongamento do espaço de educação mantido pelos colégios católicos. Atendiam ao desejo de libertação feminina crescente no período analisado, enquadrando as aspiraçôes femininas de maior escolaridade e de maior participação na vida pública, na possibilidade de exercício de um "feminismo cristão", materializado nas ações de benemerência, ressignificadas agora com o diploma superior de assistente social. ${ }^{9}$ Os homens instruídos, cultos, "bem" educados, eram também os filhos das famílias mais bem estabelecidas socialmente, estavam inscritos nas escolas superiores públicas mais prestigiadas e eram percebidos como os mais aptos a governar os demais.

Em uma sociedade industrial, na qual as qualificaçōes educacionais assumiram um papel que, até então, era prerrogativa do nascimento, o sistema de ensino se transformou no espaço onde se travam importantes lutas pela diferenciação social, conforme demonstrou Fritz Ringer (2003) para o caso de países europeus. Reconstruir estas divisões do espaço educacional paulistano permitiu verificar as oposições pertinentes a este campo de forças. Tais oposições não fazem muito sentido isoladamente e são, antes de tudo, relações de força transpostas para o universo escolar.

Face à modificação das aspirações, as hierarquias se recriam

Entre as famílias pesquisadas, a geração-pivô, neste estudo, nasceu na década de 1940 e estava acabando o ensino secundário no final da 
década de 1950. Por volta de 1960, o curso secundário, grau de escolarização alto para meninas na geração anterior, tornou-se uma exigência para as meninas destas famílias. Todas as moças da geração-pivô eram egressas das três escolas confessionais femininas pesquisadas (Perosa, 2009). A comparação entre a escolaridade de meninos e meninas nesta geração foi possível graças aos dados sobre ocupação e escolaridade de irmãos e cônjuges. No que tange aos cônjuges, é preciso considerar que o ingresso feminino no ensino superior contribuiu para alterar os padrōes de aliança matrimonial, adquirindo o diploma um peso maior nesta definição. Entre os cônjuges, dezessete eram egressos dos grandes ginásios católicos, oito dos grandes colégios privados laicos da cidade e sete eram egressos dos ginásios públicos. Elas se casaram com os egressos da escola pública, que conheceram na universidade e que faziam a escola da Politécnica da USP, seguido da Medicina e depois do Direito. Aparece ainda, entre os cônjuges, uma variação nos diplomas, cursos que não aparecem na geração anterior (Agronomia, Administração etc.). Uma variação ligada à diferenciação interna dos sistemas de ensino e da educação superior, como decorrência do processo de expansão da oferta educacional que ocorreu no país.

Entre os filhos das famílias pesquisadas, metade do meninos frequentava os grandes liceus privados e laicos, enquanto todas as meninas, suas irmãs, iam para a escola católica. A outra metade das famílias pesquisadas aqui manteve meninas e meninos nos grandes ginásios católicos da cidade. Se comparamos a educação destes meninos com a de seus pais, vemos, em pequena escala, o declínio da escolha pela escola pública no interior deste grupo social. De uma geração a outra, o número de meninos na escola pública caiu de catorze para dois casos entre as famílias consideradas. Possivelmente, trata-se de uma estratégia de evitamento entre os grupos sociais no sistema de ensino, bem descrita por estudos em outras configurações sociais (François \& Poupeau, 2000).

Até então uma exceção, o diploma superior para as mulheres tornou-se, nessa geração, se não obrigatório, altamente desejável. Seguindo a tendência das estatísticas nacionais, ${ }^{10}$ a partir dessa geração-pivô é que o nível de escolaridade entre homens e mulheres foi equiparado. Um avanço importante, mas que significa pouco se não considerarmos a hierarquia entre as carreiras e os diplomas. A chegada feminina no ensino superior brasileiro se deu, originalmente, preservando as segregaçôes entre os sexos na escolha do curso superior. ${ }^{11}$ Entre 1956 e 
A passagem pelo sistema de ensino em três gerações...

1971, a metade do contingente feminino no ensino superior estava inscrita nos cursos de Letras, Pedagogia, História, Geografia, Ciências Sociais e Psicologia e 10\%, nos cursos de Física, Química, Matemática e Biologia, habilitações estas que possuíam em comum o fato de que conduziam as mulheres ao exercício do magistério. Nos cursos tradicionalmente masculinos, tais como Direito, Engenharia e Medicina, o percentual feminino era baixo no período em questão (11\%, 6\%, 4\%, respectivamente), mas crescera, se considerarmos que, no início do século, fora próximo do zero. ${ }^{12}$ Este crescimento se deu de maneira parecida em diversos países, sobretudo nos da Europa ocidental (cf. Baudelot \& Establet, 1992; Hirata \& Maruani, 2003). Além da preservação da conotação sexual no ingresso no ensino superior e, portanto, da posse de diplomas menos rentáveis, quando se examina detalhadamente as carreiras femininas desta geração, notamos que ela se dá estritamente dentro das possibilidades impostas pelas carreiras masculinas (Faguer, 1997; Perosa, 2008).

Para a geração seguinte, filha da geração-pivô aqui analisada, os dados estatísticos mostram o acesso maciço das meninas ao ensino superior e um acentudado crescimento nas ocupações tradicionalmente masculinas (Bruschini, 2003). Os dados apresentados neste artigo permitem pensar as raízes das lutas e das tensões simbólicas que concorreram para a definição dessa difusão do ensino, na qual o nascimento e o sexo dos alunos foram, e ainda são, em certa medida, decisivos nas trajetórias individuais após a escola. $\mathrm{O}$ ingresso feminino tardio, mas progressivo, em níveis mais altos da hierarquia escolar e, gradualmente, dos grupos populares no ensino superior permite interrogar o privilégio da ordem social (o nascimento e o sexo) sobre a ordem escolar (o mérito).

Recebido e aprovado em maio de 2010.

\section{Notas}

1. A Escola Normal da Praça foi criada em 1846, a Escola Normal Primária do Brás, em 1896, e o Ginásio do Estado, em 1892 (São Paulo, 1914). Embora fosse uma formação considerada de excelente qualidade, o diploma de magistério, ao contrário do diploma de ensino secundário dos ginásios, não permitia o ingresso no ensino superior.

2. São Paulo possuía, em 1872, 31.385 habitantes. Em 1890, este número saltou para 64.934; vinte anos depois, para 239.820, quando então a cidade passou a ser a segunda mais populosa do país. Em 1920, a cidade já contabilizava uma população de 579.033. 
Em 1940, 1.318.539 era o número total de habitantes. Na década de 1950 este número atingiu a casa dos dois milhóes de habitantes, ultrapassando o Rio de Janeiro e se tornando a maior cidade brasileira (cf. Morse, 1970).

3. Em 1914, a cidade de São Paulo contava com 28 grupos escolares, instalados nos principais núcleos habitacionais da cidade: Arouche (1905), "Avenida" (1909), Barra Funda (1903), Bela Vista (1900), Belenzinho (1909), Bom Retiro (1909), Braz (1898-1º), Braz (1896-2 ${ }^{\circ}$, Braz (1908-3º), Cambuci (1908), Carmo (1894), Consolação (1911), Lapa (1909), Liberdade (1905), Maria José (1896), Mooca (1906), Pari (1905), Mooca (1914), Penha (1913), Prudente de Moraes (1895), Santana (1909), Santa Ifigênia (1896), Santo Antonio (1908), São Joaquim (1914), São João (1907), Sul da Sé (1896), Triunfo (1900), Vila Mariana (1909). O interior do estado contava com 120 grupos escolares (São Paulo, 1914).

4. Sobre as edificações dos grupos escolares como documentos da cultura material do sistema de ensino, ver Buffa e Pinto (2002).

5. O ritmo de instalação das instituições educacionais privadas se acelerou desde a reforma Rivadávia (1911), que instituiu a liberdade de ensino e a competiçăo livre, potencializando a criação de escolas oficiais. No nível primário e no nível secundário, houve o surgimento de centenas de estabelecimentos de ensino particulares, criados por professores, congregações religiosas que aportaram no Brasil e outros grupos da sociedade, entre eles os grupos de imigrantes, que passaram a comercializar o acesso à educação. Sobre as características da expansão escolar na cidade de São Paulo, ver Beisiegel (1974, 1986) e Spósito (1984).

6. A Escola Normal, embora fosse mista, em 1914, possuía 617 alunas, contra 150 alunos. No mesmo ano, o Ginásio da Capital possuía 336 alunos, todos do sexo masculino (São Paulo, 1936).

7. Memórias e biografias mostram como o Ginásio São Bento tendia a conduzir seus alunos a determinadas escolas superiores da cidade. Consultar Fausto (1997) e Montoro (2001).

8. "Um dos documentos mais influentes emitidos pelo Ministério da Educação, na década de 1930, foi o informe de 1938 sobre 'Educação profissional na Alemanha', redigido por Rodolfo Fuchs, aliado íntimo de Gustavo Capanema, no qual o autor elogia a estrita separação entre os sexos na educação vocacional alemã, o que produzia 'mulheres femininas e homens de verdade"” (cf. Weinstein, 1995, p. 152).

9. Em 1932, foi fundada, por uma congregação católica da cidade, a Escola de Serviço Social. Um ano depois, outra congregação católica abria a Faculdade de Música (1933). Estes espaços de ensino superior eram redutos femininos (cf. Perosa, 2009).

10. Até 1956, contava-se apenas 26\% de mulheres no ensino superior. Em 1966, este número saltara para 31\%, chegando a 40\% em 1971 (cf. Barroso \& Mello, 1979).

11. Como no Brasil, a conotação sexual de fileiras no interior do ensino superior ocorreu na Europa e em boa parte dos países ocidentais. A esse respeito, consultar Baudelot e Establet (1992).

12. Em 1907, as mulheres constituíam 0,24\% dos alunos de Direito, 3\% dos inscritos em Medicina e $0,47 \%$ do ensino politécnico (Barroso \& Mello, 1979).

\section{Referências}

\section{ALMEIDA, A.M.F. The formation of the elites in Brazil. Social Science Information, Paris, v. 4, n. 40, p. 585-606, 2001.}

Educ. Soc., Campinas, v. 31, n. 111, p. 391-409, abr.-jun. 2010

Disponível em <http://www.cedes.unicamp.br> 
A passagem pelo sistema de ensino em três gerações...

ALMEIDA, A.M.F. A escola dos dirigentes paulistas. Belo Horizonte: Argumento, 2009.

ANDRADE, O. Um homem sem profissão. São Paulo: Globo, 2000.

ARIÈS, P. História social da criança e da familia. Rio de Janeiro: Guanabara, 1979.

ARRUDA, M.A.N. Metrópole e cultura. São Paulo: EdusC, 2001.

ATTIAS-DONFUT, C.; LAPIERRE, N. La dynamique des générations. Communications, Paris, n. 59, p. 5-13, 1994.

ATTIAS-DONFUT, C.; LAPIERRE, N.; SEGALEN, M. Le nouvel esprit de famille. Paris: Odile Jacob, 2002.

AZANHA, J.M.P. Democratização do ensino: vicissitudes da ideia do ensino paulista. Educação \& Pesquisa, São Paulo, v. 30, n. 2, p. 335344, maio/ago. 2004.

BARROS, R.P.; FRANCO, S.; MENDONÇA, R. A recente queda da desigualdade de renda e o acelerado progresso educacional da última década. Rio de Janeiro: IPEA, 2007.

BARROS, R.P. et al. Determinantes do desempenho educacional no Brasil. Rio de Janeiro: IPEA, 2001.

BARROSO, C.; MELLO, G.N. O acesso da mulher ao ensino superior. Cadernos de Pesquisa, São Paulo, n. 15, p. 47-75, 1979.

BAUDELOT, C.; ESTABLET, R. Allez les filles! Paris: Seuil, 1992.

BAUDELOT, C.; ESTABLET, R. Avoir 30 ans en 1968 et en 1998. Paris: Seuil, 2000.

BEISIEGEL, C.R. Estado e educação popular. São Paulo: Pioneira, 1974.

BEISIEGEL, C.R. Educação e sociedade no Brasil após 1930. In: Fausto, B. O Brasil republicano. Rio de Janeiro: Difel, 1986. v. 3, p. 383-416.

BONELLI, M.G. O instituto da Ordem dos Advogados brasileiros e o Estado: a profissionalização no Brasil e os limites dos modelos centrados no mercado. Revista Brasileira de Ciências Sociais, Rio de Janeiro, v. 14, n. 39, p. 61-82, 1999. 
BOURDIEU, P. A reprodução: elementos para uma teoria do sistema de ensino. Lisboa: Vega, 1978.

BOURDIEU, P. La noblesse d'État. Paris: Éditions du Minuit, 1989.

BOURDIEU, P. Razôes práticas. Campinas: Papirus, 1997.

BOURDIEU, P. A dominação masculina. Rio de Janeiro: Bertrand Brasil, 1999.

BRUNO, E.S. Memória da cidade de São Paulo: depoimento de moradores e visitantes/1553-1958. São Paulo: Secretaria Municipal de Cultura, Departamento do Patrimônio Histórico, 1981.

BRUSCHINI, C.; LOMBARDI, M.R. Mulheres e homens no mercado de trabalho brasileiro: um retrato dos anos 1990. In: Hirata, H.; Maruani, M. As novas fronteiras da desigualdade. São Paulo: SenaC, 2003. p. 323-361.

BUFFA, E.; PINTO, G.A. Arquitetura e educação. São Carlos: EDUFSCAR; Brasília, DF: INEP, 2002.

CARVAlHO, J.M. A escola de Minas de Ouro Preto. Belo Horizonte: UFMG, 2002. 219p.

COELHO, E.C. As profissóes imperiais: medicina, engenharia e advocacia no Rio de Janeiro, 1822-1930. Rio de Janeiro: Record, 1999.

COOKSON, P.; PERSELL, C. Preparing for power. New York: Basic Books, 1985.

FAGUER, J.-P. Os efeitos de uma "educação total": um colégio jesuíta, 1960. Educação \& Sociedade, Campinas, v. 18, n. 58, p. 9-53, 1997 a.

FAGUER, J.-P. Esposa e colaboradora. In: Bourdieu, P. (Org.). A miséria do mundo. Petrópolis: Vozes, 1997b.

FAORO, R. Os donos do poder: formação do patronato político brasileiro. 3. ed. Rio de Janeiro: Globo, 2001.

FAUSTO, B. Negócios e ócios: histórias da imigração. São Paulo: Cia. das Letras, 1997.

FERNANDES, P.P. (Org.). Guia dos documentos históricos na cidade de São Paulo, 1554/1954. São Paulo: HUCiTeC; NEPS, 1998. 
A passagem pelo sistema de ensino em três gerações...

FRANÇOIS, J.-C.; POUPEAU, F. Les determinants socio-spatiaux du placement scolaire. Revue Française de Sociologie, Paris, v. 49, n. 1, p. 93-126, 2008.

HAIDAR, M.L.M. O ensino secundário no Império. São Paulo: EDUsP, 2008.

HASENBALG, C.; SILVA, N.V. Origens e destinos. Rio de Janeiro: Topbooks, 2003.

HIRATA, H.; MARUANI, M. As novas fronteiras da desigualdade. São Paulo: SENAC, 2003.

INSTITUTO BRASILEIRO DE GEOGRAFIA E ESTATÍSTICA (IBGE). Estatísticas do século XX. Recenseamento de 1920: "População das capitais da União, segundo o grau de instrução e a idade". Rio de Janeiro: IBGE, 2004.

MENEZES FILHO, N. A evolução da educação no Brasil e seu impacto no mercado de trabalho. 2001. Disponível em: <http://www. anj.org.br/jornaleeducacao/biblioteca/publicacoes/A\%20Evolucao\%20 da $\% 20$ educacao $\% 20$ no $\% 20$ Brasil $\% 20$ e $\% 20$ seu $\%$ 20impacto $\% 20$ no\%20Mercado\%20de\%20trabalho.pdf/view> Acesso em: 25 jun. 2010 .

MILLS, W.C. White collar: the American middle classes. Nova York: Oxford University, 1951. p. 259-278.

MONTORO, A.F. Memórias em linha reta. São Paulo: SEnAC, 2001. MORSE, R. Formação histórica de São Paulo. São Paulo: DIfel, 1970. MOURA, Pe. L. A educação católica no Brasil. São Paulo: Loyola, 2000. MUEL-DREYFUS, F. Vichy et l'éternel féminin. Paris: Seuil, 1996.

PEROSA, G.S. Educação diferenciada e trajetórias de profissionalização feminina. Tempo Social, São Paulo, v. 20, n. 1, p. 51-68, 2008.

PEROSA, G.S. Escola e destinos femininos. Belo Horizonte: Argumento, 2009.

PEROSA, G.S. Grupos familiares, investimentos educacionais e o mercado escolar em São Paulo. Pro-Posiçôes, Campinas, v. 15, n. 2, p. $61-75,2004$. 
PERSELL, C.H.; COOKSON, PW. Pensionnats d'élite: ethnographie d'une transmission de pouvoir. Actes de la Recherch en Science Sociales, Paris, n. 138, p. 56-65, 2001.

PINÇON, M.; PINÇON-CHARLOT, M. Voyage en grande bourgeoisie. Paris: Quadrige; PUF, 1997.

RINGER, F. Education and society in modern Europe. Bloomington: Indiana University, 1979.

RINGER, F. La segmentation des systèmes d'enseignement. Actes de la Recherche en Sciences Sociales, Paris, n. 149, p. 6-18, 2003.

SÃO PAUlO (Estado). Anuário do Ensino do Estado de São Paulo. São Paulo: Diretoria Geral da Instrução Pública, 1914. p. 518 -519.

SÃO PAULO (Estado). Distribuição dos estabelecimentos de ensino secundário, oficiais e particulares no Estado de São Paulo. In: SÃO PAULO (Estado). Anuário do Ensino do Estado de São Paulo 1935/1936. São Paulo: Diretoria Geral de Instrução Pública, 1936. p. 261.

SAINT-MARTIN, M.; GHEORGHIU, M. Éducation et frontiéres socials: un grand bricolage. Paris: Michalon, 2010.

SCOTT, J. Genre: une categorie utile d'analyse historique. Les Cahiers $d u$ GRIF, Paris, n. 37/38, p. 125-153, 1988.

SPÓSITO, M. O povo vai à escola. São Paulo: Loyola, 1984.

TRIGO, M.H.B. Espaços e tempos vividos: estudo sobre os códigos de sociabilidade e relações de gênero na Faculdade de Filosofia da USP (1934-1970). 1997. Tese (Doutorado em Filosofia) - Faculdade de Filosofia, Letras e Ciências Humanas, Universidade de São Paulo, São Paulo.

WEBER, M. Os letrados chineses. In: WeBER, M. Ensaios de sociologia. Rio de Janeiro: Zahar, 1974. p. 471-501.

WEINSTEIN, B. As mulheres trabalhadoras em São Paulo: de operárias não qualificadas a esposas profissionais. Cadernos Pagu, Campinas, n. 4, 143-171, 1995. 
